\title{
Role of Exchange Transfusion In Dapsone Poisoning
}

\section{Authors \\ Dr Nilesh Bastewad ${ }^{1}$, Dr Harshal Bhitkar ${ }^{2}$, Dr Pramod Umarji ${ }^{3}$, Dr Deelip Kadam ${ }^{4}$}

\begin{abstract}
Suicidal ingestion of Dapsone can lead to severe methemoglobinemia. Exchange Transfusion decreases Meth-Hb level. We present a young female with suicidal ingestion of Dapsone who responded to Exchange Transfusion.
\end{abstract}

\section{Introduction}

Dapsone is a synthetic sulfone increasingly used in the treatment of a wide variety of dermatological disorders in tropical world1. Because of its use in various conditions, its toxicity is commonly seen in adults. However, dapsone intoxication in children is usually accidental and invariably fatal. The toxicity is directly related to the methemoglobin (met-Hb) levels in blood2. Here we report a case of dapsoneinduced Methemoglobinemia successfully treated with Exchange Transfusion, intermittent intravenous methylene blue, ascorbic acid and activated charcoal.

\section{Case History}

A 15 yrs old female presented to emergency after sucidal ingestion of 24 tablets (2.4 g) of dapsone, with complaints of breathlessness, palpitation, headache, sweating, bluish discoloration of lips and nails for 2 hrs. On examination, she had Tachypnea, Tachycardia and cyanosed. pulse rate was 140/min, RR 30/min, BP 140/90 $\mathrm{mmHg}, \mathrm{SPo} 270 \%$ at the time of admission and METH Hb- 21\%. ECG- Rate 140, regular (sinus tachycardia). ABGA s/o Metabolic acidosis. The patient was initially managed by gastric lavage followed by continuous oxygen by face mask. activated charcoal was given through nasogastric tube.Inj.Methylene blue 1 $\mathrm{mg} / \mathrm{kg}$ along with Inj. Ascorbic acid $250 \mathrm{mg}$ three times a day. But still the patient was irritable and cyanosed. Methylene blue and ascorbic acid therapy were continued in the same dose. Irrespective of all above treatment the cyanosis was persist and patient becomes more irritable. So relatives was counseled about Exchange transfusion. After 2 cycles of Exchange transfusion the patient was improved. Her symptoms was relieved on $2^{\text {nd }}$ day. By $8^{\text {th }}$ day the patient was completely recovered. Her METH- $\mathrm{Hb}$ level was $2 \%$ and Spo2 level was also improved to 94\%. Patient was discharged..

\section{Discussion}

Dapsone was first introduced as an effective chemotherapeutic agent for leprosy. Other uses of dapsone are dermatitis herpetiformis, panniculitis due to alpha-1 antitrypsin deficiency and Pneumocystis cariniipneumonia in HIV patients. Dapsone poisoning in children is usually accidental and results not only in methemoglobinemia but also hemolysis, hepatitis, coma, seizures and metabolic acidosis ${ }^{3}$ Met- $\mathrm{Hb}$ is an oxidation product of $\mathrm{Hb}$ in 
which there is an oxidized ferric iron in sixth coordination position instead of reduced ferrous iron in normal $\mathrm{Hb}$. This oxidized ferric iron containing site is then bound to a water molecule or to a hydroxyl group ${ }^{4}$. This complex is dark brown and unable to transport oxygen with a leftward shift in oxygen dissociation curve, thus leading to a decreased tissue oxygenation with subsequent hypoxic features ${ }^{4}$ Methemoglobinemia, an infrequent condition can be congenital due to deficiency of red cell NADH reductase or be induced by several toxic compounds, such as chlorates, inorganic and organic nitrites, and with drugs, like local anesthetics and sulpha drugs, including dapsone. The clinical manifestations are directly related to concentration of met- $\mathrm{Hb}$ and is usually fatal when more than about $30 \%$ of $\mathrm{Hb}$ is converted to met- $\mathrm{Hb}^{2}$. We presented young female patient had met-Hb level of $21 \%$. The standard management of orally ingested drug dapsone induced methemoglobinemia includes gastric lavage, administration of charcoal, methylene blue, ascorbic acid and exchange transfusion. Methylene blue is the drug of choice in the treatment of methemoglobinemia. Methylene blue when given intravenoulsy is rapidly reduced to leuco-methylene blue by the enzyme NADPH-met-Hbreductase which reduces the met-Hb back to $\mathrm{Hb}$ by a cyclic reaction ${ }^{\mathbf{5}}$. The prompt treatment with repeated doses of methylene blue brought about the reversal of meth-Hb level ${ }^{6}$. The recurrence had been due to continued absorption of dapsone from the gastrointestinal tract and formation of its toxic metabolites ${ }^{4}$. The exchange transfusion had been reported to be very effective in the management of methemoglobinemia ${ }^{7}$ but was later found to be of minor benefit, probably due to large volume of distribution of dapsone $\mathbf{8}^{\mathbf{2}}$.

\section{References}

1. Linakis JG, Shannon M, Woolf A, Sax C. Recurrent methemoglobinemia after acute dapsone intoxication in a child. $J$ Emerg Med 1990;8:351-2.
2. Mac Donald RD, McGuigan MA. Acute dapsone intoxication: A pediatric case report. Pediatr sEmerg Care 1997; 13:1279.

3. Sahoo SK, Tripathy N, Debi BP. Acute fatal DDS poisoning. Lepr India 1979;51:244-8.

4. Price D. Methemoglobinemia. In: Goldfrank LR, Flomenbaum NE, Lewin NA, Weisman RS, Howland MA, Hoffman RS, editors. Goldfrank'sToxicologic emergencies, 6th ed. Stamford: Appleton \& Lange; 1998. P-150719.

5. Disanto AR, Wagner JG. Pharmacokinetics of highly ionized drugs. II: Methylene blueabsorption, metabolism and excretion in man and dog after oral absorption. $J$ PharmSci1972;61:1086-90.

6. Ferguson AJ, Lavery GG. Deliberate self poisoning with dapsone: A case report and summary of relevant pharmacology and treatment. Anaesthesia1997;52:359-63.

7. Kumar A, Antony TJ, Kurein KM, Taneja LN, Mohan M, Anand NK. Exchange transfusion of dapsone poisoning. Indian Pediatr1998;25:798-800.

8. Berlin G, Brodin B, Hilden JO, Martensson J. Acute dapsone intoxication: A case treated with continuous infusion of methylene blue, forced diuresis and plasma exchange. $J$ ToxicolClinToxicol1984;22:537-48. 